\title{
Aneurysm of main left coronary artery
}

\author{
MARK KESSLER, ROBERT I HAMBY, JOSEPH HILSENRATH \\ From the Department of Medicine, Division of Cardiology, Long Island fewish-Hillside Medical Center, \\ New Hyde Park, New York, Queens Hospital Center Affiliation, famaica, New York, and School of \\ Medicine, Health Sciences Center, State University of New York at Stony Brook, Stony Brook, New York, \\ USA
}

SUMMARY A 57-year-old man presented with exertional chest pain, and was found to have a saccular, lohulated aneurysm of the left main coronary artery associated with severe atherosclerotic vascular disease. This is the third similar case reported and the first case of atherosclerotic origin. All symptoms were relieved by coronary artery bypass surgery.

Angiographic studies have shown that coronary artery aneurysms occur in 1 to 2.5 per cent of patients with coronary artery disease..$^{1-4}$ Multiple aetiologies have been reported, most frequently atherosclerotic, ${ }^{56}$ and/or congenital. ${ }^{5-7}$ Other reported causes include bacterial infection, ${ }^{6}$ syphilis ${ }^{6}$ septic embolism,${ }^{7}$ trauma ${ }^{3}{ }^{8}$ dissection, ${ }^{9}$ polyarteritis nodosa, ${ }^{10}$ scleroderma, ${ }^{11}$ Ehlers-Danlos syndrome, ${ }^{12}$ Marfan's syndrome, ${ }^{9}$ metastatic tumour, ${ }^{7}$ cystic medionecrosis, ${ }^{10}$ and mucocutaneous lymph node syndrome. ${ }^{13} 14$

We describe an aneurysm involving the main left coronary artery; to our knowledge, only three such angiographically documented cases have been previously reported in adults. ${ }^{15-17}$

\section{Case report}

This was the first hospital admission for a 57-yearold white man who had been in excellent health until one-and-a-half months before admission. At that time, he developed exertional chest pain associated with dyspnoea and relieved by rest. Because of increasing frequency and duration of this chest pain, in spite of medical treatment, he was admitted for cardiac catheterisation. There was no history of heart disease or hypertension. He had smoked cigarettes for 25 years. Both his father and mother had died of atherosclerotic heart disease at the ages of 65 and 73, respectively. Two brothers died of atherosclerotic heart disease at the ages of 50 and 52 , and one sister, age 63 , had had a myocardial infarction and was alive.

On physical examination, blood pressure was $120 / 80 \mathrm{mmHg}$, and pulse 50 per minute and regular. All peripheral pulses were palpable. No jugular venous distension was noted and carotid upstrokes were normal. Lungs were clear and cardiac examination did not reveal any abnormality. The chest $x$-ray and electrocardiogram were within normal limits. The blood chemistry, including a two-hour postprandial serum glucose were normal. The cholesterol was 4 and triglycerides $1 \mathrm{mmol} / \mathrm{l}$. The cardiac catheterisation was performed with retrograde left ventriculography and selective coronary angiography using Judkins catheters. A left main coronary artery lesion was noted superimposed on severe triple vessel disease. Multiple projections showed a lobulated, septated aneurysm limited to the left main coronary artery (Fig.).

The patient underwent quadruple saphenous vein coronary artery bypass surgery. Two weeks later, a postoperative cardiac catheterisation was performed and all four bypass grafts (left anterior descending, circumflex, intermediate, and posterior descending arteries) were found to be patent and functioning well. The postoperative course was uncomplicated.

\section{Comment}

The majority of coronary artery aneurysms have been reported to occur in the right coronary artery, with the circumflex being the next most frequently involved vessel and the left anterior descending artery the most often spared.1 ${ }^{16}$ To the best of our knowledge, the angiographic diagnosis of a left main coronary artery aneurysm in an adult has been reported three times previously. ${ }^{15-17}$ One case $^{15}$ involved a young woman (23 years old), who 
presented with exertional chest pain and a continuous, soft murmur. On catheterisation, she was found to have a saccular aneurysmal dilatation of the left main coronary artery, communicating with another intramuscular aneurysm sac. There were no other associated diseases and this lesion was felt to be congenital. The second case ${ }^{16}$ was a 33year-old woman, who presented with a murmur

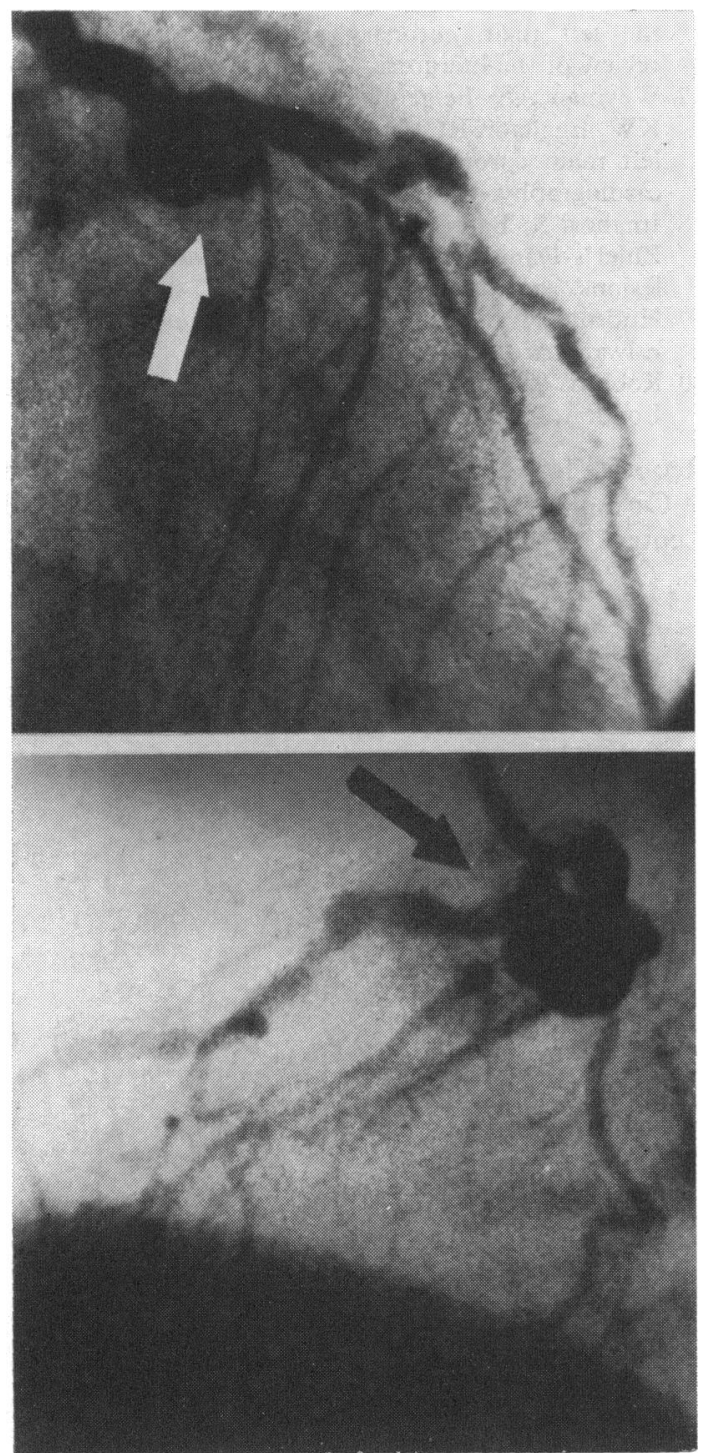

Fig. Selective left coronary angiogram in the right anterior oblique (upper) and left anterior oblique (lower) projections showing an aneurysm (arrow) of the main left coronary artery just proximal to its bifurcation. and was found to have supravalvular aortic stenosis, congenital aneurysm of the left ventricular apex, and aneurysmal dilatation of the main left coronary artery. Her only symptom or associated finding was an embolic cerebral vascular accident. The third case $^{17}$ does not give any clinical data. By contrast, the case reported here is of a middle-aged man with a single saccular septated aneurysm of the left main coronary artery associated with atherosclerotic coronary artery disease. No murmurs were present and no symptoms could be attributed to the aneurysm directly. The atherosclerotic vascular disease was sufficiently severe to account for the exertional chest pain that led to his admission. The 23-year-old woman, ${ }^{15}$ and the patient presented here underwent coronary bypass, with relief of their symptoms. An earlier report ${ }^{4}$ showed no deaths among 30 patients with coronary aneurysm 18 months after coronary bypass surgery. Markis and associates ${ }^{3}$ reported a 15 per cent annual mortality in a two-year follow-up of 20 patients treated medically. Several children have been reported with aneurysms of the left main coronary artery associated with mucocutaneous lymph node syndrome, a disease which seems to have a predilection for the main coronary arteries. ${ }^{13} 14$

When examined histologically, weakening of the media was noted as a major cause of arterial dilatation leading to an aneurysm and/or ectasia. ${ }^{118} 19$ Swanton et al. ${ }^{1}$ showed severe atherosclerotic involvement with extensive intimal fibrosis leading to weakening of the media in a case of coronary ectasia with atherosclerotic heart disease. Imahori et al. ${ }^{18}$ showed mucopolysaccharide deposition with intimal sclerosis in the media in Ehlers-Danlos syndrome. Medial involvement in syphilis, polyarteritis nodosa, Marfan's syndrome, and cystic medionecrosis has been well documented. ${ }^{20}$ This weakening of the vessel media can easily be recognised as an aetiological factor leading to arterial dilatation.

The present case of a main left coronary artery aneurysm of probable atherosclerotic origin in an adult is, to our knowledge, the first to be reported.

\section{References}

1 Swanton RH, Lea Thomas M, Jenkins BS, WebbPeploe MM, Williams BT. Coronary artery ectasiaa variant occlusive coronary arteriosclerosis. $\mathrm{Br}$ Heart F 1978; 40: 393-400.

2 Befeler B, Aranda JM, Embi A, Mullin FL, ElSherif N, Lassara R. Coronary artery aneurysms. Am F Med 1977; 62: 597-607.

3 Markis JE, Joffe CD, Cohn PF, Feen DJ, Herman MV, Gorlin R. Clinical significance of coronary arterial ectasia. Am $\mathcal{F}$ Cardiol 1976; 37: 217-22. 
4 Aintablian A, Hamby RI, Hoffman I, Kramer RJ. Coronary ectasia: incidence and results of coronary bypass surgery. Am Heart $\mathcal{f}$ 1978; 96: 309-15.

5 Björk L. Ectasia of coronary arteries. Radiology 1966; 87: 33-4.

6 Daoud AS, Pankin D, Tulgan H, Florentin RA. Aneurysms of the coronary artery: report of ten cases and review of literature. Am F Cardiol 1963; 11: 228-37.

7 Crocker DW, Sobin S, Thernas WC. Aneurysms of the coronary arteries: report of three cases in infants and review of the literature. Am $\mathcal{F}$ Pathol 1957; 33: 819-37.

8 Konecke LL, Spitzer S, Mason D, Kasparian H, James PM. Traumatic aneurysm of the left coronary artery. Am $\mathcal{F}$ Cardiol 1971; 27 : 221-3.

9 McKeown F. Dissecting aneurysm of the coronary artery in arachnodactyly. Br Heart $\mathcal{f} 1960$; 22: 434-6.

10 Boschetti AE, Levine A. Cystic medionecrosis with dissecting aneurysm of coronary arteries. Arch Intern Med 1958; 102: 562-70.

11 Chaithiraphan S, Goldberg E, O'Reilly M, Jootar P. Multiple aneurysms of coronary artery in sclerodermal heart disease. Angiology 1973; 24: 86-93.

12 Shiro I, Bannerman RM, Graf CJ, Brennan JC. Ehler's-Danlos syndrome with multiple arterial lesions. Am F Med 1969; 47: 967-77.

13 Yoshikawa J, Yanagihara K, Owaki T, et al. Crosssectional echocardiographic diagnosis of coronary artery aneurysms in patients with the mucocutaneous lymph node syndrome. Circulation 1979; 59: 133-9.

14 Kato H, Koike S, Yamamoto M, Ito Y, Yano E. Coronary aneurysms in infants and young children with acute febrile mucocutaneous lymph node syndrome. F Pediatr 1975; 80: 892-8.

15 Seabra-Gomes R, Somerville J, Ross DN, Emanuel $R$, Parker DJ, Wong $M$. Congenital coronary artery aneurysms. Br Heart $\mathcal{F} 1974$; 36: 329-35.

16 Gupta MP, Zoneraich S, Aintablian A, Mehta J. Congenital aneurysm of the left ventricle associated with supravalvular aortic stenosis and aneurysm of the left main coronary artery. Case report and review of the literature. Angiology 1975; 26: 269-75.

17 Weyman AE, Feigenbaum H, Dillon JC, Johnston KW, Eggleton RC. Noninvasive visualization of the left main coronary artery by cross-sectional echocardiography. Circulation 1976; 54: 169-74.

18 Imahori S, Bannerman RM, Graf CJ, Brennan JC. Ehler's-Danlos syndrome with multiple arterial lesions. Am f Med 1969; 47: 967-77.

19 Hudson REB. Cardiovascular pathology. London: Edward Arnold, 1965.

20 Robbins SL. Pathologic basis of disease. Philadelphia, London, Toronto: WB Saunders, 1974.

Requests for reprints to Dr Mark Kessler, Division of Cardiology, Long Island Jewish-Hillside Medical Center, New Hyde Park, New York 11042, USA. 